\title{
Effect of Aqueous Leaf Extract of Dissotis Roundifolia on Plasma Glucose and Creatinine Concentration in Normal Albino Rats
}

\author{
V. E. Boloya ${ }^{a}$, E. P. Tawaria*, B. E. Kasia ${ }^{a}$, S. I. Boye ${ }^{\text {b }}$, T. P. Proph ${ }^{b}$ \\ ${ }^{a}$ perebi8@yahoo.com \\ ${ }^{a}$ Department of Chemical Pathology, Faculty of Basic Medical Sciences, College of Health Science, Niger Delat University, Bayelsa \\ State, Nigeria \\ bDepartment of Biochemistry,, Faculty of Basic Medical Sciences, College of Health Science, Niger Delat University, Bayelsa State, \\ Nigeria
}

\begin{abstract}
Dissotis rotundifolia is a broad spectrum medicinal plant that has received worldwide recognition. This study was designed to investigate the effect of aqueous leaf extract of Dissotis rotundifolia on plasma glucose and creatinine level in normal albino rats. A total of 6 albino wistar rats each weighing 150g were assembled and randomly divided into 2 groups (control and tests) consisting of 3 rats each. The control group received pelleted growers mash and distilled water all through the period of experiment while the test group received $2 \mathrm{ml} / \mathrm{kg}$ body weight of extract twice daily. Blood samples was collected into lithium heparin bottle for creatinine and sodium oxalate tube for glucose determination. The data obtained were subjected to statistical analysis using SPSS version 20. Results showed a significant increase in the mean plasma glucose and creatinine levels in rats treated with Dissotis rotundifolia compared with normal control group. This suggests a deleterious effect of Dissostis rotundifolia at the investigated dosage and thus, may not be safe for oral consumption. Hence, there is need for further studies in this regard in order to ascertain the safety of Dissostis rotundifolia.
\end{abstract}

Keywords: Dissotis rotundifolia; Glucose; Creatinine; medicinal plants; Albino Wistar rat

\section{INTRODUCTION}

Medicinal plants are commonly used in treating and preventing specific ailments and diseases, and are generally considered to play a beneficial role in healthcare (Aja et al., 2015). Makanjuola et al., (2014), reported that approximately $80 \%$ of the developing world's population meets their Primary Healthcare needs through traditional medicine. The demand and dependency on medicinal plants as remedy for different ailment is steadily increasing not only in developed countries but also in industrialized nations.

Dissotis rotundifolia (sm) Triana belongs to the family Melastomataceae. These plants exhibit a wide range of biological and pharmacological activities such as antiinflammatory, anti-anemic, anti-malaria, anti-microbial, anti-diabetic and so many properties (Ayevbuomwan et al., 2017). It is wide spread in Nigeria and other West African countries. Dissotisrotundifolia is a creeping herb with purple or sometimes pinkish flowers. Its medicinal uses include treatment of coughs, tooth ache, migraines, jaundices, blennorrhoea, bronchitis, fever, pneumonia, asthma, tubercular conditions, yellow fever, and diarrhoea (Balogun and Owoseni, 2013). The antitrypanosomal potential of the crude 
extract at different doses has been established in rats treated orally or intraperitoneally. The plant also has been found to be rich in ascorbic acid (Vitamin C) when compared with some common garden fruits and vegetables (Balogun and Owoseni, 2013). It is used in East Africa for the treatment of bilharzias and in Cameroun, the leaves are used for dysentery (Aja et al., 2015). In tropical Africa, the whole plant is used as a remedy for rheumatism and yaws and as an antihelmintic and in Liberia for diarrhea (Abere et al., 2010). Hot water extract of Dissotisrotundifolia given orally is used for hookworm infestations (Ansah et al., 2016).

Creatinine is a by-product of muscle metabolism in which creatine in the muscle is converted nonenzymatically to creatinine (Bhattacharjya and Goswami, 2016). Because the total body content of creatine is fairly constant, there is a continual production of creatinine and a continual excretion of it in the urine (Allen, 2012). The typical $70 \mathrm{~kg}$ adult man produces about $2 \mathrm{~g}$ of creatinine per day (Bhattacharjya and Goswami, 2016). Creatinine is a more specific indicator of renal glomerular filtration rate than blood urea nitrogen (BUN), which is more easily affected by nonrenal factors (Allen, 2012).

Plasma glucose level is the concentration of glucose present in the blood of humans and other animals (Cox and Nelson, 2013). Elevated glucose levels (hyperglycemia) may also occur with pancreatic neoplasm, hyperthyroidism, and adrenal cortical hyperfunction as well as other disorders (Lehninger et al., 2017). Decreased glucose levels (hypoglycemia) may result from excessive insulin therapy or various liver diseases.

This research aims to determine the effect of aqueous leaf extract of dissotisrotundifolia on plasma glucose and creatinine level in normal albino rats.

\section{MATERIALS AND METHOD \\ Chemicals/Reagents}

The chemicals and reagents used in this study include distilled water, methylated spirits, glucose kit, Creatinine kit (product of Randox Laboratory Limited). All other reagents used were of standard analytical grade.

\section{Preparation of Dissotisrotundifolia Leaf Extract}

The plant Dissotisrotundifolia was obtained from the Niger Delta University premises. After collecting the plants, they were thoroughly washed and air dried. $100 \mathrm{~g}$ of the fresh leaves was homogenised using laboratory mortal and pistol and mixed with 1liter of distilled water at $1 \mathrm{~g} / 10 \mathrm{ml}$ distilled water. The active ingredient of the homogenised sample was extracted using clean cheese cloth. The filtrate was stored in a clean bottle and refrigerated under $3^{\circ} \mathrm{C} .2 \mathrm{ml} / \mathrm{kg}$ body weight of the filtrate was administered to the rat twice daily (12 hourly). 


\section{Administration of Extract}

The plant extracts were administered to the test rats according to their weight. The extract was administered twice daily (morning and evening) at the dose of $2 \mathrm{ml} / \mathrm{kg}$ body weight.

\section{Experimental Animals}

Normal female albino rats between the ages of 6-7weeks were used for this experiment. The rats were obtained from the animal house, in the Faculty of Basic Medical Science, College of Health Science, Niger Delta University, Wilberforce Island AmassomaBayelsa State. The rats were moved from the animal house to the Department of Biochemistry where they were maintained and allowed free access to pelleted growers mash and clean water for $u$ period of two week acclimatizes to the new environment.

\section{Feed}

The rats were fed with pelleted growers mash weighing $150 \mathrm{~g}$ twice daily.

\section{Experimental Design}

After acclimatization for two weeks and basal test was carried out on the rat, they were starved overnight (fasting) and then grouped randomly into two groups containing three rats each.

\section{Groups 1}

Control-This group was given pelleted growers mash and distilled water all through the period of experiment.

\section{Group 2}

Test-Required amount of extract was administered orally at $2 \mathrm{ml} / \mathrm{kg}$ body weight using gavage, twice daily for 15 days. Pelleted growers mash and distilled water were also given to them throughout the experiment

\section{Collection of Blood}

Little Vaseline was applied on the tail of the rat and then massaged gently towards the tip for some time until the top showed evidence of blood accumulation. Thereafter, the tip of the tail was incised and blood was collected immediately with lithium heparin bottle for creatinine and sodium oxalate tube for glucose determination.

\section{Assays of Biochemical Parameters}

The Glucose and Creatinine assays were preformed according to the procedure described by Randox Laboratory Ltd.

\section{Histological Assessment of Tissue}

The rats were sacrificed and dissected to obtain the heart, liver and kidney for histological 
studies. The tissue samples were immediately preserved by immersion into $10 \%$ formalin. The fixed tissue sample were cleared in xylene and embedded in paraffin wax and sections were cut using 5-micron in a rotatory microtome. The sections were then examined using the light microscope after staining with hematoxylin and eosin dye and interpreted by an expert histologist.

\section{Statistical Analysis}

All measurement will be expressed as Mean \pm Standard deviation. The statistical significance will be evaluated using SPSS version 20, (One-way Analysis of Variance (ANOVA). Values are considered statistically significant when $\mathrm{P}<0.05$.

\section{RESULTS}

Table 1 and Figure 1 showed that the plasma glucose concentration increased progressively from Day 0 to Day 15. When compared to the test group a statistical $(\mathrm{P}<0.05)$ increase was observed in from Day 0 to Day 15.

Table 1: Mean plasma glucose concentration $(\mathrm{mg} / \mathrm{dl})$ of control and test rats administered aqueous extract of Dissostisrotundifoliafor15 days.

\begin{tabular}{llllll}
\hline & DAY 0 & DAY 1 & DAY 5 & DAY 10 & DAY 15 \\
\hline CONTROL & $52.21 \pm 14.81^{\mathrm{a}}$ & $44.00 \pm 17.40^{\mathrm{a}}$ & $41.09 \pm 15.12^{\mathrm{a}}$ & $38.05 \pm 16.23^{\mathrm{a}}$ & $33.85 \pm 22.77^{\mathrm{a}}$ \\
TEST & $58.18 \pm 7.82^{\mathrm{b}}$ & $67.34 \pm 18.23^{\mathrm{b}}$ & $70.08 \pm 13.99^{\mathrm{b}}$ & $88.91 \pm 29.45^{\mathrm{c}}$ & $95.40 \pm 11.82^{\mathrm{d}}$
\end{tabular}

Values are reported as mean \pm SD of triplicate determinations. Values are statistically different from control at $\mathrm{P}<0.05^{*}$ One Way Analysis of Variance (ANOVA). Values with the same superscript are not statistically different.

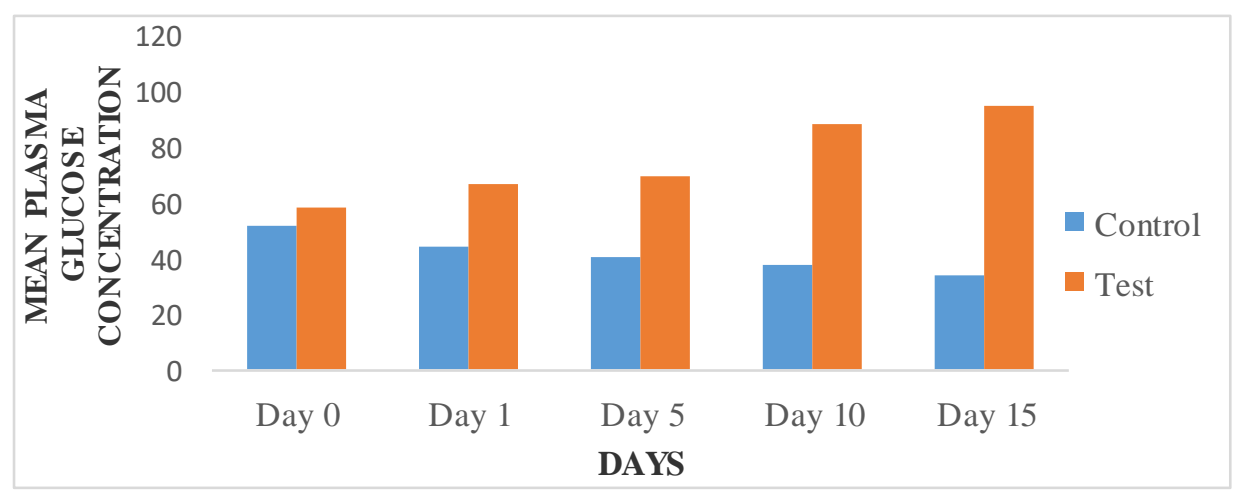

Figure 1: Mean plasma glucose concentration (mg/dl) of control and test rats administered aqueous extract of Dissostis rotundifolia for15 days. 
Table 2 and Figure 2 revealed that a significant increase in creatinine was observed in control from Day 0 to day 15. When compared to control, a statistical $(\mathrm{p}<0.05)$ increase was observed in the test group from Day 0 to day 15 .

Table 2: Mean plasma creatinine concentration $(\mathrm{mg} / \mathrm{dl})$ of control and test rats administered aqueous extract of Dissostis rotundifolia for 15 days.

\begin{tabular}{llllll}
\hline & DAY 0 & DAY 1 & DAY 5 & DAY 10 & DAY 15 \\
\hline CONTROL & $29.85 \pm 18.91^{\mathrm{a}}$ & $27.47 \pm 24.38^{\mathrm{a}}$ & $23.80 \pm 10.10^{\mathrm{a}}$ & $15.66 \pm 6.90^{\mathrm{a}}$ & $52.24 \pm 31.32^{\mathrm{a}}$ \\
TEST & $37.83 \pm 5.76^{\mathrm{b}}$ & $44.38 \pm 20.67^{\mathrm{b}}$ & $47.19 \pm 13.02^{\mathrm{b}}$ & $52.96 \pm 26.91^{\mathrm{b}}$ & $54.47 \pm 33.79^{\mathrm{b}}$ \\
\hline
\end{tabular}

Values are reported as mean \pm SD of triplicate determinations. Values are statistically different from control at $\mathrm{P}<0.05 *$ One Way Analysis of Variance (ANOVA). Values with the same superscript are not statistically different.

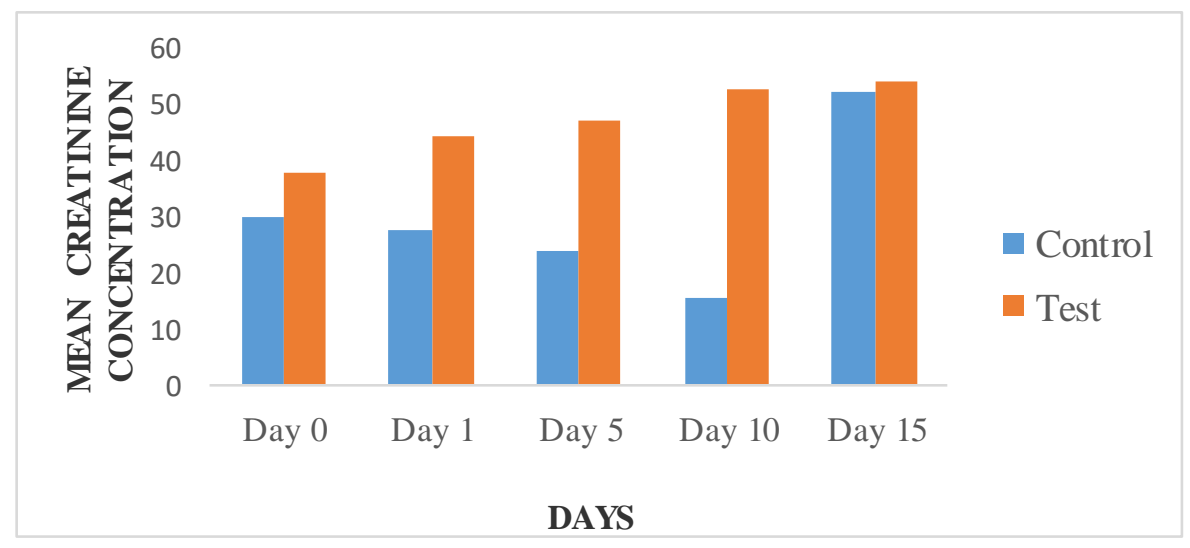

Figure 2: Mean plasma creatinine concentration $(\mathrm{mg} / \mathrm{dl})$ of control and test rats administered aqueous extract of Dissostisrotundifoliafor 15 days.

From the result table 3 showed that the rats in the control progressively increased in weight from day 0 to 15 . It was also observed that the rats in the test group increased in weight from day 0 to day 15 . 
Table 3: Mean weight (g) of rats administered with aqueous extract of Dissostisrotundifolia.

\begin{tabular}{llllll}
\hline & DAY 0 & DAY 1 & DAY 5 & DAY 10 & DAY 15 \\
\hline Control & $131^{\mathrm{a}}$ & $131^{\mathrm{a}}$ & $142^{\mathrm{a}}$ & $151^{\mathrm{a}}$ & $162^{\mathrm{a}}$ \\
Test & $146.2^{\mathrm{a}}$ & $149.2^{\mathrm{a}}$ & $150.0^{\mathrm{a}}$ & $156.6^{\mathrm{a}}$ & $166.7^{\mathrm{a}}$ \\
\hline
\end{tabular}

Values are reported as mean \pm SD of triplicate determinations. Values are statistically different from control at $\mathrm{P}<0.05^{*}$ One Way Analysis of Variance (ANOVA). Values with the same superscript are not statistically different.

Figure 3: Mean weight (g) of rats administered aqueous extract of Dissostisrotundifolia

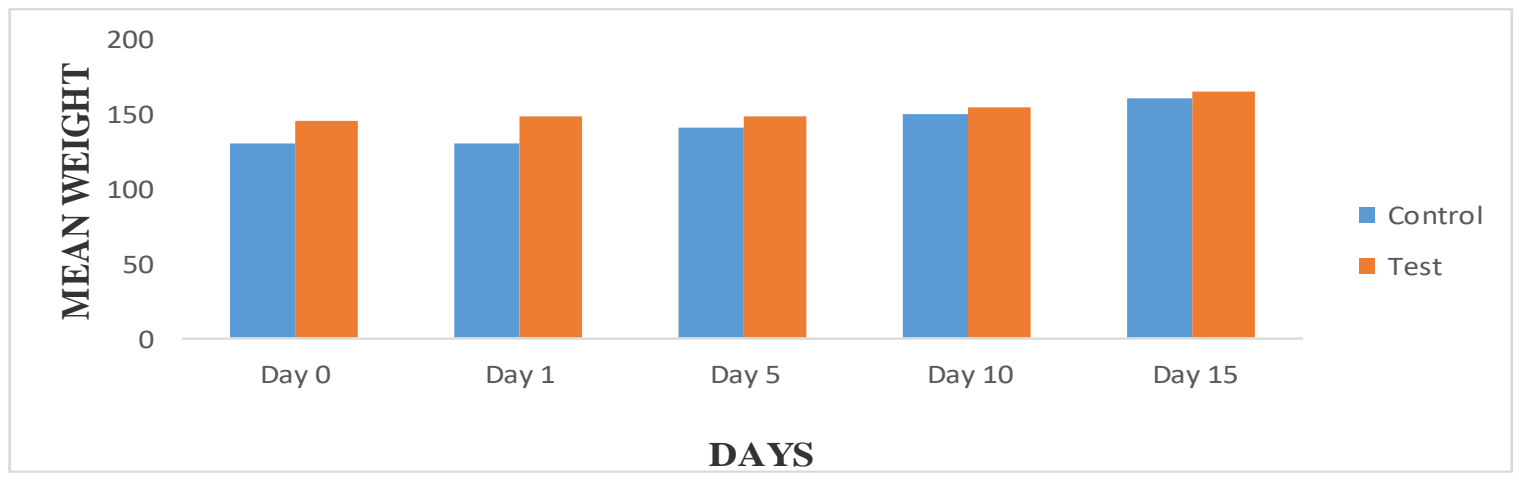

Liver: Histopathological sections of the liver of the control animal showed normal plates of hepatocytes separated by sinusoids () unlike those of test animals that received the extract. Photomicrograph of the liver tissue showing central vein, hepatocytes and sinusoids consistent with normal histology of the liver. The TEST group shows infiltration of inflammatory cells around the central vein. Also seen are prominent kupffer cells. Substance administered is hepatotoxic
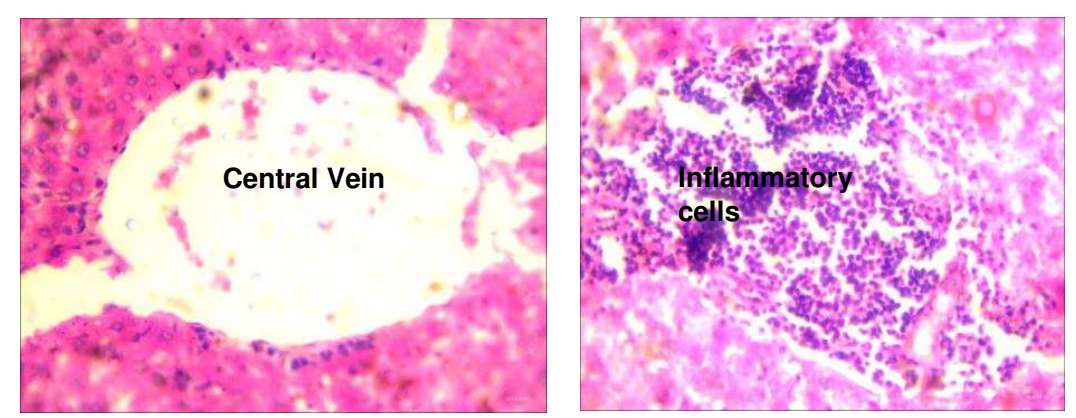

PLATE 1: Haematoxylin and Eosin stain liver Tissue, X 400 Magnification 


\section{Kidney:}

Photomicrograph of the kidney tissue stained with haematoxylin and eosin. The CONTROL kidney slides shows normal glomerulus showing Bowmans space and messengial cells, the tubules display normal epithelium consistent with normal histology of the kidney. TEST slide membranous defeat of the glomerulus with cells leaking into the stroma. Substance administered is toxic to the kidney.
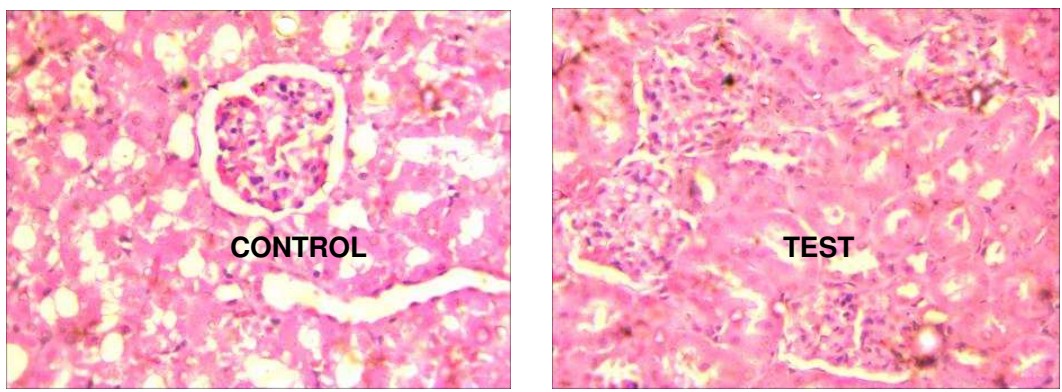

PLATE 2: Haematoxylin and Eosin stain kidney Tissue, X 400 Magnification

Heart: Photomicrograph of the heart tissue showing normal histology. Both Test and control are consistent with normal histology of the heart. Substance administered is nontoxic to the tissue.
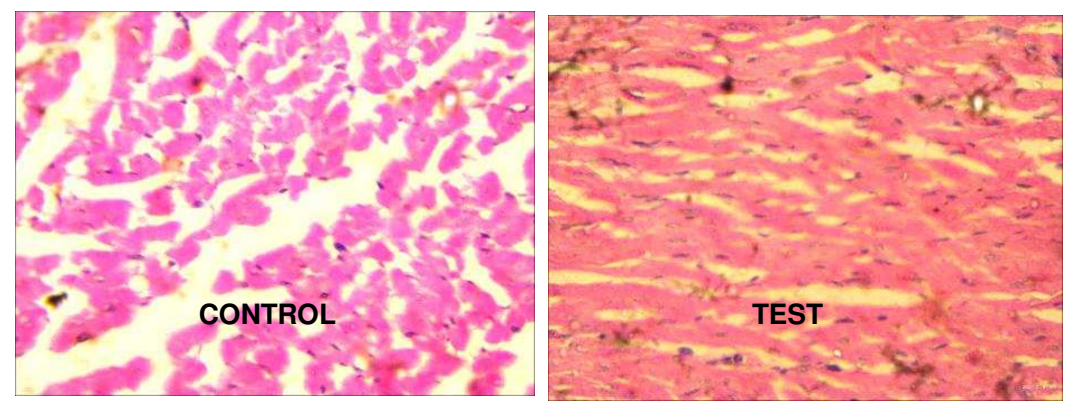

\section{PLATE 3: Haematoxylin and Eosin stain heart Tissue, X 400 Magnification}

\section{DISCUSSION}

Medicinal plants are of great importance to the health of individuals and communities and their medicinal values lie in some chemical substances that produce definite physiological actions on the human body (Ahn, 2017). Plants synthesize hundreds of chemical compounds for functions including defense against insects, fungi, diseases, and herbivorous mammals in the example of salicylic acid, as a hormone in plant defense. Numerous phytochemicals with potential and established biological activity have been identified. The 
phytochemical content and pharmacological actions of many plants having medicinal potential remain unassessed by rigorous scientific research to define efficacy and safety (Ahn, 2017).

The preliminary analysis of the plasma glucose and creatinine of the normal albino rats showed glucose concentration ranging from $38-52 \mathrm{mg} / \mathrm{dl}$ and creatinine ranged from $15-$ $52 \mathrm{mg} / \mathrm{dl}$. Continual administration of the extract brought about a significant increase in the mean plasma glucose which ranged from $58-95 \mathrm{mg} / \mathrm{dl}$ and creatinine level ranged from 38$54 \mathrm{mg} / \mathrm{dl}$. The increase in plasma glucose and creatinine concentration may be as a result of the plant extract. Glucose is a simple sugar that circulates in the blood of animals as blood sugar. Glucose serves as a primary fuel for energy production, especially for the brain, muscles and several other body organs and tissues. Glucose also serves as a building block for larger structural molecules of the body, such as glycoproteins and glycolipids (Clarke and Foster, 2012).Elevated plasma glucose concentration (hyperglycemia) a condition in which an excessive amount of glucose circulates in the blood plasma. Symptoms include frequent hunger, frequent thirst, increased volume of urination, blurred vision, fatigue, restlessness, weight loss, poor wound healing, dry mouth, and dry or itchy skin (Geijselaers et al., 2017). Reduced plasma glucose concentration (hypoglycemia) is when blood sugar decreases to below normal levels. This may result in a variety of symptoms including clumsiness, trouble talking, confusion, loss of consciousness, seizures, or death (Yanai et al., 2015).

Result from this study showed that the aqueous extract of Dissostisrotundifoliacaused a significant increase in plasma glucose concentrations in days $1,5,10$, and 15, when compared with the normal control (Table 1). This decrease could have been due to the plant inducing the production of insulin by mobilizing glucose into the cell. Early report on the phytochemical and antimicrobial effect of Dissotisrotundifolia by Balogun and Owoseni (2013) showed the presence of saponin, tannin, flavonoid, anthraquinone, steroid, and cardiac glycosides. This result is not in agreement with those reported by Mohamed et al., (2019) which showed a significant decrease in plasma glucose level in STZ-induced diabetic albino rats following oral administration of ethanol and aqueous-ethanol extracts of R. communis leaves.

This finding suggests that extracts exhibited a potent hyperglycemic activity which may be due to the presence of alkaloids, flavonoids and saponins which could act synergistically and independently as a stimulant for the inhibition of insulin resulting to the significant increase in glucose level.

Creatinine is a waste product formed in muscle by creatine metabolism. Creatine is synthesized in the liver, passes into the circulation and is taken up almost entirely by skeletal muscle (Ezeugwunne et al., 2017). Its retention in the blood is evidence of kidney impairment. Serum creatinine is an important indicator of renal health because it is an 
easily-measured by-product of muscle metabolism. Creatinine itself is an important biomolecule because it is a major by-product of energy usage in muscle via a biological system involving creatine, phosphocreatine and adenosine triphosphate (Ezeugwunne et al., 2017). Creatinine is chiefly filtered out of the blood by the kidneys. There is little or no tubular reabsorption of creatinine. If the filtering of the kidney is deficient, creatinine blood levels rise (Jhee et al., 2018). Therefore, creatinine levels in blood and urine may be used to calculate the creatinine clearance, which reflects the glomerular filtration rate (Allen, 2014).

Result from this study showed that the aqueous extract of Dissostisrotundifoliacaused a significant increase in creatinine concentrations in day $1,5,10$, and 15 , when compared with the normal control (Table 2). Similar report by Ogbodo, et al., (2018) revealed a significant increase $(\mathrm{p}=0.000)$ of mean serum creatinine level in rats following treatment with phyllanthusamarus when compared with the control subjects (129.20 \pm 1.93 ; 83.90 \pm 10.14 ). Eweka and Adaze, (2011) reported a distortion in renal structures after oral administration of P. amarus leaf extract on the kidneys of adult wistar rats. The observed increase in creatinine level suggest deficiency in glomerular filtration and tubular secretion. Furthermore, the aqueous extract of Dissostisrotundifolia caused a significant increase in the mean weight of the test rats when compared with normal control.

\section{CONCLUSION}

In conclusion, the administration of aqueous extract of Dissostisrotundifoliashowed a significant increase in the mean plasma glucose and creatinine level with a corresponding increase in the mean weight of rats when compared to the normal control. This suggests a deleterious effect of Dissostis rotundifolia at the investigated dosage and thus, may not be safe for oral consumption. Hence, there is need for further studies in this regard in order to ascertain the safety of Dissostis rotundifolia. Furthermore, biochemical and histopathological investigations are needed to explore the possible use of different doses of this extract and their constituents.

\section{REFERENCES}

Abere, T. A., Okoto, P. E., and Agoreyo, F. O. (2010). Antidiarrhoea and toxicological evaluation of the leaf extract of Dissotisrotundifoliatriana (Melastomataceae). BMCComplementaryandAlternativeMedicine. 10(71): 1-7

Ahn, K. (2017). The Worldwide trend of using botanical drug and strategies for developing global drugs. BMB Reports. 50 (3): 111-116

Aja, P. M., Alum, E. U., Ezeani, N. N., Ibiam, U. A., and Egwu, C. (2015). Comparative phytochemical evaluation of Dissotisrotundifolia root and leaf. Global Vet. 14(3): 418-424

Allen, P. J. (2012). Creatine metabolism and psychiatric disorders: Does creatine supplementation have therapeutic value. Neuroscience and Biobehaviour 
Review. 36(5): 1442-1462.

Ansah, C., Adinortey, M. B., Asiedu-Larbi, J., Aboagye, B., Asante, D. B., and Nyarko, A. K. (2016). In vivo assessment of the toxic potential of Dissotisrotundifolia whole plant extract in Sprague-Dawley rats. Asian Pacific Journal of Tropical Biomedicine. 6(7): 574-579.

Ayevbuomwan, M. E., Irabor, F., Amiebenomoh, A. R. and Omoregie, E. S. (2017). Comparative study of proximate composition, in vitro antioxidant activity and phytochemical constituents of methanol extract of dissotisrotundifolia leaf and detariummicrocarpumstem bark. Nigerian Journal Life Science. 7(2): 2-17

Balogun, O. S. and Owoseni A. A. (2013). Phytochemical and antimicrobial investigation of Dissotisrotundifolia (sm) Triana. An Indian Journal. 9(2): 77-80

Bhattacharjya, J. and Goswami, B. (2016). Comparative Study of Serum Creatinine Level in Normal and Hypertensive Persons. International Journal of Scientific Study 4(2): $1-16$.

Clarke, S. F. and Foster, J. R. (2012). A history of blood glucose meters and their role in self-monitoring of diabetes mellitus. British journal of biomedical science. 69 (2): 83-93.

Cox, D. L. and Nelson, M. M. (2013). Lehninger principles of biochemistry (6th ed.). W.H. Freeman. New York. 949-950.

Eweka, A. O., and Adaze E. (2011). Effects of Oral Administration of PhyllanthusamarusLeaf Extract on the Kidneys of Adult Wistar Rats-A Histological Study. African Journal of Traditional, Complementary and Alternative Medicine. 8(3): 307-311.

Ezeugwunne, I. P., Eriugo, R. C., Ogbodo, E. C., Oguaka, V. N., Analike, R. A., Madukwe, D. U. P., Okwara, E. C., Onyegbule, O. A., Ezego, A. I., and Okeke, K. U. (2017). Effect of sidacorymbosa leaf extract on serum uric acid, urea and creatinine levels of alloxan-induced diabetic albino wistar rats. International Journal of Basic, Applied and Innovative Research. 6(2): 51-57

Geijselaers, S., Sep, S., Claessens, D., Schram, M., Boxtel, V. M. and Henry, R. (2017). "The Role of Hyperglycemia, Insulin Resistance, and Blood Pressure in DiabetesAssociated Differences in Cognitive Performance". The Maastricht Study, Diabetes Care. 40(11): 1537-1547.

Jhee, J. H., Hwang, S. D., Song, H. and Lee, S. W. (2018). Upper Normal Serum Creatinine Concentrations as a Predictor for Chronic Kidney Disease: Analysis of 14 Years' Korean Genome and Epidemiology Study (KoGES). Journal of Clinical Medicine. 7: 390

Lehninger, A., Nelson, D., and Cox, M. (2017). Lehninger Principles of Biochemistry (7th ed.). W. H. Freeman. New York. 929-930.

Makanjuola, V. O., Tams, G. E., and Ipinniwa, D. A. (2014). The effect of methanolic extract of Dissotisrotundifolia on cadmium induced testicular damage in whistar 
rats. Journal of Pharmacology. 4(7): 56-65

Mohamed, A. Gad-Elkareem, M., Elkhatim, H., Abdelgadir, O., Badawy, M. and Kadri, .A. (2019). Potential antidiabetic effect of ethanolic and aqueous-ethanolic extracts of Ricinuscommunis leaves on streptozotocin-induced diabetes in rats. Peer Journal. 7(2): 41-61

Ogbodo, E. C., Ibeme, B. C., Ezeugwunne, I. P., Okpogba, A. N., Analike, R. A., Oguaka, V. N., and Amah, A. K. (20118). Amarus Leaf Extract on The Serum Creatinine, Urea, and Uric Acid Levels of Alloxan-Induced Diabetic Albino Wistar Rats in College of Health Sciences and Technology, NnamdiAzikiwe University, Nnewi Campus, Anambra State, Nigeria. International Journal of Trend in Research and Development. 5(1): 394-413.

Yanai, H., Adachi, H., Katsuyama, H., Moriyama, S., Hamasaki, H. and Sako, A. (2015). Causative anti-diabetic drugs and the underlying clinical factors for hypoglycemia in patients with diabetes. World Journal of Diabetes. 6(1): 30-36. 